\title{
Subroutines and visual line information processing*
}

\author{
JEHOSUA FRIEDMANN $\dagger$ and MARK S. MAYZNER \\ New York University, Bronx, N.Y. 10453
}

An experiment was designed to detect the existence of line-size and line-orientation processing subroutines. The results suggest that the visual system utilizes two distinct line-processing subroutines: a horizontal subroutine and a vertical subroutine. However, the sizes were handled by an individual subroutine executed repeatedly. It was also found that each increment of $3 \mathrm{msec}$ significantly increased line-recognition performance.

In the last 15 years, many researchers have investigated the problem of pattern recognition. Such research has been concerned mostly with a particular, simplified version of the general problem of perception and pattern recognition, namely the problem of assigning the appropriate class identification to an isolated two-dimensional array of discrete symbols. The bulk of the research has concentrated on the recognition of letters of the alphabet and, at times, other visual patterns.

In particular, computer scientists investigating pattern-recognition systems have usually been interested in producing devices that would improve the efficiency of data intake by a computer. Despite many efforts (Bledsoe \& Browning, 1959; Uhr \& Vossler, 1963; Marzocco, 1965; Tou \& Gonzales, 1972), the problem of cursive script recognition by a mechanical device has not been solved. Very rarely has an attempt been made to incorporate into such procedures features that have any known relation to biological pattern-recognition systems. Nevertheless, there is a surprising degree of similarity between many concepts and procedures devised by computer scientists, on the one hand, and the models proposed by psychologists and the processes discovered by neurophysiological researchers, on the other.

In this paper, we were concerned with the processing mechanisms the visual system brings to bear when lines of various sizes and orientations were presented to the system, for varying display on-times followed immediately by a noise field, on a computer-based cathode ray tube display system. Specifically, our examination endeavored to detect the existence of distinct subroutines, that is, line-size and line-orientation processing subroutines.

These subroutines, if properly understood. could be useful in the eventual design of a machine pattern-recognition system. The straight line was chosen

*This research was supported by Grant GB-22785 from the National Science Foundation to the last author.

+Present address: Kingsborough College of the City University of New York. Department of Mathematics and Computer Science, Oriental Boulevard. Manhattan Beach. Brooklyn. N.Y. 11235 . as the basic stimulus, since it is assumed that any curve can be approximated by a sequence of line segments. The concept of subroutine is assumed as expounded by Mayzner (1972).

We like to focus our attention on such questions as: (1) Are horizontal, vertical, and 45-deg lines handled each by a different subroutine? (2) Are different sizes processed by different subroutines? (3) Do these subroutines differ from person to person? A tentative answer to these questions constitutes the principal goal of the present paper.

\section{METHOD \\ Subjects}

Four Ss, graduate students selected at random at the University Heights campus of New York University. served as Ss.

\section{Apparatus}

The stimuli were presented on a cathode ray tube (CRT) display console driven by a PDP-8/E digital computer. A complete description of a similar system, hardware, and its associated software is found in previous publications (Mayzner, Tresselt. \& Helfer, 1967; Mayzner, 1968).

The CRT used was Type VR 14 manufactured by the Digital Equipment Corporation. The display surface was coated with an ultrashort-persistence phosphor (P24), having a decay time on the order of a few microseconds, giving essentially instant decay. Display luminance was $1 \mathrm{~mL}$ for a steady state display, as measured with a Gamma Scientific photometric system (Model $2020 \mathrm{EA}$ ).

We should note that an appropriate computer program. which allowed us to display horizontal lines. vertical lines, and 45-deg lines inclined counterclockwise to the horizontal line, was written for this project.

\section{Materials}

The basic stimulus set consisted of vertical lines. 45-deg lines counterclockwise from the horizontal, horizontal lines, and a square noise field, as shown in Table 1 . All lines consisted of 17 points, generated by intensifying 17 points from the bottom up through the center of a 17 by 17 matrix of points.

The display of a line was immediately followed by a noise field, thus adapting a procedure developed by Mayzner (1972). This noise field was produced by intensifying all points in the 17 by 17 matrix of points.

We would like to note that special contingencies were taken for the diagonal line to ensure that all line sizes were equal, as shown in Table 1 . These lines were generated in a random fashion to neutralize any effect arising from this arrangement. All lines were generated randomly by utilizing a manufacturer-supplied random generator.

Two matrix sizes were employed, 2.25 and 5.0 in. in length of the side of a square.

\section{Procedure}

The $\mathrm{S}$ was dark adapted for $15 \mathrm{~min}$. and seated $6 \mathrm{ft}$ away facing the CRT display unit. One second after a bell. generated by the computer system. rang. a line chosen randomly from our basic set was displayed on the console unit for 1 of 10 different display on-times. i.e.. $0-9 \mathrm{msec}^{1}$ for any of the two sizes employed. i.e. 2.25 or $5.0 \mathrm{in}$. in length. and for any of the three directions employed. followed immediately by the noise field. as shown in Table 1. for a duration of $500 \mathrm{msec}$. The $\mathrm{S}$ recorded his responses by depressing an appropriate key on the Teletype. 
Table 1

The Lines and the Noise Field Employed in Our Study

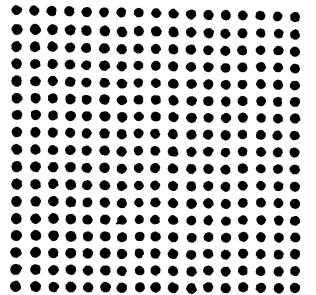

17 Points by 17 Points

Noise Field

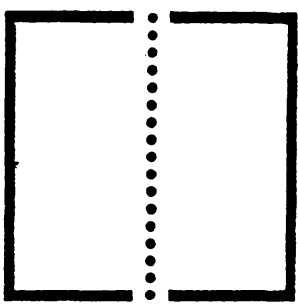

17 Points Vertical Line

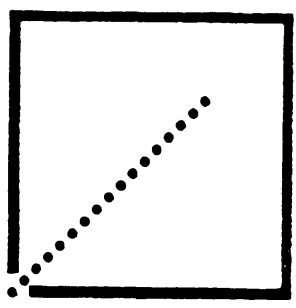

17 Points 45-Deg Line Form a

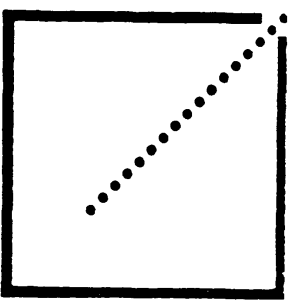

17 Points 45-Deg Line Form b

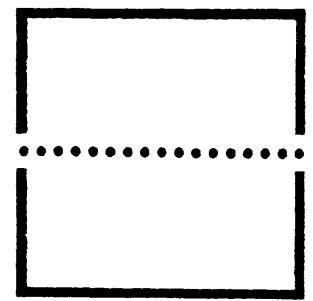

17 Points Horizontal Line

Four factors were selected for intensive study: Factor $P$ (persons), at four fixed qualitative levels; Factor $\mathrm{S}$ (size). at two fixed quantitative levels; Factor D (direction), at three fixed qualitative levels involving horizontal lines, vertical lines, and 45-deg lines inclined counterclockwise to the horizontal: Factor T (time), at 10 fixed quantitative levels. One replication consisted of 60 , i.e.. $2 \times 3 \times 10$. repetitions. Each $\mathrm{S}$ received 30 replications, or a total of 1.800 repetitions. Each session consisted of 10 replications, or 600 repetitions. For the four Ss. this amounted to a total of 7,200 repetitions. At the end of each session, the Teletype printed a summary of Ss' responses. As a result, three repetitions were available for the ANOVA.

\section{RESULTS}

The ANOVA showed that Factors P, S, D, and T were highly significant at the .01 level $(F=30.948$, $\mathrm{df}=3 / 480, \mathrm{p}<.001 ; \mathrm{F}=39.325, \mathrm{df}=1 / 480, \mathrm{p}<.001 ;$ $\mathrm{F}=6.785 . \mathrm{df}=2 / 480, \mathrm{p}<.001 ; \mathrm{F}=34.628, \mathrm{df}=9 / 480$, $\mathrm{p}<.001)$, respectively. $\mathrm{P}$ by $\mathrm{S}$ was found to be highly significant $(F=59.232, \mathrm{df}=3 / 480, p<.001)$. $P$ by $D, P$ by T, D by T, S by T, D by T, P by S by D, and P by $S$ by $T$ were found to be significant ( $F=2.675$, $\mathrm{df}=27+80, p<.001: F=2.759 . \mathrm{df}=94+80 . p<.004:$ $\mathrm{F}=2.194 . \mathrm{df}=18 / 480 . \mathrm{p}<.003: \mathrm{F}=3.366 . \mathrm{df}=6 / 480$. $\mathrm{p}<.003: \mathrm{F}=3.6+1 . \mathrm{df}=27 / 480 . \mathrm{p}<.001$. respectively.

\section{DISCUSSION}

The significance of the $P$ factor indicates that the line- and size-processing subroutines differ from $S$ to $S$. This finding raises a fundamental question: If $S$ s vary in their recognition scores. would this variation be different from $S$ to $S$, or would different Ss show similar orderings in recognition performance?-thus implying. perhaps. that the underlying processing subroutines are similar from $S$ to $S$.

To provide a first assessment. correct recognition scores for the three lines involved were obtained for all Ss. These scores were summed across all three sessions, and a rank-difference correlation (rho) was computed. Six correlations were calculated. and the values were $.34 .35, .60, .18, .40$. and .60 . Those results suggest a moderate degree of similarity somewhat lower than those found by Mayzner (1972).

The sizes differed significantly. We favor the interpretation that the visual system utilizes a single basic-size subroutine. It is assumed that this subroutine can process a line up to a maximum length. This length is constant for a sy'stem and varies from person to person. When a line is presented to the visual system, it invokes the size subroutine which is executed once twice or for as many times as necessary to process the line. Therefore. a line of larger size should take more time to process than one of a smaller size. Our results substantiate this conclusion. since we obtained much higher recognition scores for the smaller size as compared to the larger size. Mayzner (1972) found that the letters T. L. K, X. and the like yielded some of the highest correct recognition scores. In contrast, letters like C. G. B. and O yielded some of the lowest correct recognition scores. Thus, it seems plausible that a letter composed of straight-line segments invokes the size subroutine fewer times than a letter with a relatively complex structure involving line curvature and mixes of straight-line and curved segments. since a curvature can be approvimated by many small line segments.

In the ANOVA, we found that the directions differed significantly. However, this raises a question concerning which directions are different and which can be attributed to a common population. The Duncan test showed that only the vertical and horizontal directions differed significantly. This suggests that the visual system utilizes two distinct directional processing subroutines, a horizontal subroutine and a vertical subroutine. This finding agrees with the conclusions of Sutherland (1957. 1963a, b) and Dodwell (1971. p. 74), that octopi and rats have vertical and horizontal analyzers but none for other inclinations. However, this finding disagrees with the following results: (1) Leibowitz (1953) established the "superiority of visual acuity obtained with a grating test object oriented vertically or horizontally over values obtained with oblique orientation [p. 902]." (2) Campbell \& Maffei (1970) found the average evoked potential of oscillating gratings to be greater when they were vertical or horizontal than when they were 45 deg. (3) Maffei \& Campbell (1970) found that the amplitude of the potential evoked by a moving grating. recorded from the occipital scalp. was less when it is oblique than when it was vertical or horizontal. (4) Wade (1972) studied the effects of line orientation on afterimage duration. It was found that. for binocularly generated afterimages, vertical and horizontal lines tended to be visible longer than 45-deg lines.

The time factor was found to be significant. Results obtained by the Duncan method indicate that each increase of about $3 \mathrm{msec}$ increased performance on line recognition sharply. Thus. we may assume that whatever processing subroutines the visual system employ's, each 3-msec display on-time increases the probability that these subroutines will produce a correct line-recognition response. A similar result was obtained by Mayzner (1972) utilizing letters of the alphabet. 
The interaction of $\mathrm{P}$ by $\mathrm{S}$ was found to be highly significant. indicating that the effects of Ss differ at different sizes. This finding is not surprising. since people are known to vary in their abilities to see objects placed some distance away. It is interesting to note, as a result of a Duncan test. that for a particular $S$ there is also a significant difference in correct recognition scores when the visual system is presented with different sizes.

\section{REFERENCES}

Bledsoe, W. W., \& Browning, I. Pattern recognition and reading by machine. Proceedings of the Eastern Joint Computer Conference, 1959, 16, 225-232.

Campbell, F. W., \& Maffei, L. Electrophysiological evidence for the existence of orientation and size detectors in the human visual system. Journal of Physiology, 1970, 207, 635-652.

Dodwell, P. C. Visual pattern recognition. New York: Holt, Rinehart \& Winston, 1971.

Leibowitz, H. Some observations and theory on the variation of visual acuity with the orientation of the test object. Journal of the Optical Society of America, 1953,43,902-905.

Maffei, L., \& Campbell, F. W. Neurophysiological localization of the vertical and horizontal visual coordinates in man. Science, 1970, 167, 386-387.

Marzocco, F. N. Computer recognition of handwritten first names. IEEE Transactions on Electronic Computers, 1965. 210-217.

Mayzner, $M$. S. The research potential of a computer-based cathode-ray tube display system. Behavior Research Methods \& Instrumentation, 1968, 1, 41-43.

Mayzner, M. S. Visual information processing of alphabetic inputs. Psychonomic Monograph Supplements, 1972, 4(13, Whole No. 61), 239-243.

Mayzner, M S Tresselt, M. E. \& Helfer, M. S, A research strategy for studying for certain effects of very fast sequential input rates on the visual system. Psychonomic Monograph Supplements, 1967, 2(7, Whole No. 23), 91-108.

Sutherland, N. S. Visual discrimination of shape by octopus. British Journal of Psychology, 1957, 48, 55-70.

Sutherland, N. S. Cat's ability to discriminate oblique rectangles. Science, 1963a, 139, 209-210.

Sutherland, N. S. Shape discrimination and receptive fields. Nature, $1963 \mathrm{~b}, 197,118-122$.

Tou, J. T., \& Gonzalez, R. C. Automatic recognition of handwritten characters via feature extraction and multi-level decision. International Journal of Computer \& Information Sciences, 1972, 1, 43-66.

Uhr, L., \& Vossler, C. Pattern recognition program that generates, evaluates, and adjusts its own operators. In E. A. Feigenbaum and J. Feldman (Eds.), Computers and thought. New York: McGraw-Hill, 1963. Pp. 251-268.

Wade, N. J. Orientation effects on line afterimages. Perception \& Psychoph ysics, 1972, 12, 409-416.

1. 0 msec means no display.

\section{NOTE}

(Received for publication May 17, 1973.)

\section{Instrumental and contingent saccharin-licking in rats: Response deprivation and reinforcement*}

\section{JAMES ALLISON and WILLIAM TIMBERLAKE Indiana L'niversity. Bloomington. Ind. 47401}

It has been suggested that an instrumental response

*The research was supported in part by U.S. Public Health Service Grant MH-11470 to James Allison. will increase above its baseline if and only if the contingency schedule deprives the $S$ of the contingent response. Several experiments are reported in support of this contention. The principal finding was that instrumental licking of a $.4 \%$ saccharin solution was increased above its baseline by the contingent 